NASA Technical Memorandum 79323

\title{
LASER ANEMOMETER MEASUREMENTS \\ IN A TRANSUNIC AXIAL FLOW \\ COMPRESSOR ROTOR
}

Anthony J. Strazisar and

$J$. Anthony Powell

Lew is Research Center

Cleveland, Ohio

Prepared for the

Twenty-fifth Annual International Gas 'Turbine Conference and the Twenty-second Annual Fluids Engineering Conference sponsored by the American Society of Mechanical Engineers New Orleans, Louisiana, March 9-13, 1980 
Anthony J. Strazlsar and J. Anthony Powel1

National Aeronaut $1 \mathrm{cs}$ and Space Administration Lew1s Research Cent: $r$ Cleveland, Ohto

\section{ABSTRACT}

A laser anomometer system employing an efflclent data acquisition technique has been used to make measurements upstream, within, and downstream of the compressor rotor. A fluorescent dye technique allowed measurements within endwali boundary layers. Adjustable laser bean orfentation minimized shadowed regions and enabled radial velocity measurements outside of the blade row. The flow phenomena investigated include flow varlations from passage to passage, the rotor shock system, three-dimensional flows in the blade wake, and the developwent of the outer endwall buundary layer. Laser anemometer measurements are compared to a numerical solution of the streamfunction equations and to measurements made with conventional instrumentation.

\section{INTRODUCTION}

Advances in the aerodynamic technology of turbomachinery are dependent on obtaining a comprehensive understanding of the complex phystcal phonomena which occur within the blade passages. Progress is being attained through improvements in both analytic and experimental techniques. With the increased avallability of large scale computers significant advances in computational methods for compressor design and analysis are being made. As ad ances in numerical methods continue, there is an increasing need to make detailed flow measurements inside blade rows. Such measurements w1l determine flow phenomena such as the distribution of tuming and losses which are required inputs for some numerical methods. They will also generate data for use in verffying numertcal solutions.

Cascade tests and the use of rutating instrumentation in low-speed machines are two experimental approsches to the measurement of intra-blade flowfields. Howaver, these approaches cannot provide data on the combined effects of high Mach number and high rotational speeds. High-response pressure measurements and non-intrusive optical measurement technlques such as laser anemometry and holographic interferumetry are extending flow measurement capabilities in the high-speed testing regime beyond those avallable with conventional low-response instrumentation. Applications of lager anemometer (LA) systems to axlal-flow turbomachinery employing fringe-type anemometers have been reported in [1-3]. hppl Ications involving time-of-flight anemometers have been reported in $[4]$.

Th1s paper describes the application of a LA system to a transonic axial-flow compressor rotor. The results of several types of measurements whtch demonstrate the systen's capability of measuring velocity and flow angle in a rotating blade row are discussed. However a comprehensive evaluation of the flow in this transonic compressor is beyond the scope of the present paper. A detalled description of this LA system is contained in [5]. Since transonic compressor testing requires * slgnificant expenditure of both manpower and energy, a rapid data acquisition technique has been de- veloped in order to minimize running time. The incorporation of four degrees of freedom in the laser beam orlentation enables measurement of the radial component of velocity in some cases and the minimizetion of reglons blocked from optical access by the complex blade geometry.

\section{TEST COMPRESSOR AND INSTRUMITATION}

The test rotor of the present study was designed as an Inlet rotur for a core compressor. The rotor de$81 \mathrm{gn}$ pressure ratio and mass flow are 1.67 and 215 $\mathrm{kg} / \mathrm{m}^{2} / \mathrm{s}$, respectively, at a tip speed of $426 \mathrm{~m} / \mathrm{s}$. The tip relative Mach number is 1.4 at design speed. The rotor has 52 blades, a tip chord length of $44.6 \mathrm{~mm}$, and a tip solidity of 1.48 . The inlet tip diameter 18508 the and the hub-t1p radius ratio is 0.7 . For the $L A$ application reported herein, the rotor was tested without inlet guide vanes and without a stator blade row. This configuration eliminates the circumferential variation In the flowfield induced by the stationary blade rows and thereby simplifies data acquisition and analysis.

Optical access is provided by a glass window which is 102 long in the axial direction and 51 wide (11 degrees arc) in the circumferential direction. The window terial is 3 thick commercial window glass formed to the outer endwall contour. Static blade t1p clearance was set at $1 \mathrm{~mm}$ under the window. Window washing is performed about once an hour during compressor operation by infecting automative window washing fluid Into the endwall boundary layer through a row of $0.5 \mathrm{~mm}$ holes located $230 \mathrm{~mm}$ upstream of the window.

Laser anemometer measurements were made along the design streamsurfaces shown in F18. 1. Measurements are distributed at axial locations between $z=-25.4$ and $z=50.8$ as shown along streamsurface 2 . Conventional probe survey measurements were made at stations 1 and 2 using a 6.4 min diameter combination probe. The probe used contains a thermocouple, total pressure tube, and null balancing static pressure holes for measurement of total temerature, total pressure, and flow angle. Detalls of the conventional survey data acquisition and reduction system are given in [6]. The operating points at which LA surveys were performed are shown in the performance map for the rotor as measured using the conventional instrumentation (F1g. 2).

\section{LASER ANEMOMETER SYSTEM}

The laser anemometer is a single-channe1, dualbeam system with on-axis backscatter 11 ght collection. The LA system optical layout 18 shown in Fig. 3. The laser light source is a $1.6 \mathrm{~W}$ argon-ion laser operating at $514.5 \mathrm{sm}$. The beam crossing angle is 2.825 degrees and the fringe spacing is $10.4 \mu \mathrm{m}$. The probe volume diameter based on the $1 / \mathrm{e}^{2}$ intensity points $18125 \mathrm{\mu m}$. The length of common intersection of the crossing beams is about $4 \mathrm{~mm}$. The effective length of the probe volwe is reduced to about 2 ma by placing a mask on the central portion of the focusing lens located in front 
of the photomultiplier tube. Backacatter 11 ght $18 \mathrm{col}$ lected through an 11 degree cone angle.

The entire optical syetem 1s nounted on an $x-y$ travarsing table which is used to get the probe volume axial and radial position. A rotatable beam aplitter 18 used to rotate the plane of the laser beams for measurement of velocity componente at various angles from the axial direct10n. The beans nominally enter the compressor rotor in the radial direction. A beam director mirror is used to direct the beam away from the radial direction by \pm 10 degrees to ninimize shadowed reglons caused by blade twist as shown in $\mathrm{PIg} .4$. Without variable bean direction, $20 \%$ to $30 \%$ of the blade-to-blade pessage at the hub would be blocked due to blade twist at actions $M$ and BB. Another advantage offered by the vartable beam direction 18 that $1 t$ glves some capability of measuring radisl velocity com ponents.

Keasurements to within 1 of the endwalls are made possible by using a fluorescent dye seed material and an optcal filter. Wichout the fluorescent seed, reflected 11ght from the endwall surfaces prevents measurements at radial positions less than $10 \mathrm{~mm}$ from efther endwall. Seed particles are generated by sprayatomization and are injected into the inlet through a $6.4 \mathrm{~mm}$ dlameter tube located $460 \mathrm{~mm}$ upstrean of the rotor face. The seed material consists of rhodamine 66 dye dissolved in a benzyl alcohol, ethylene $81 \mathrm{ycol}$ solution [7]. When seed particle containing this dye crosses the iA fringe system the particle absorbs the green incident 1ight and fluoresces orange. An orangepass filter placed in front of the photomultiplier tube optically filters out green 11ght reflected from blade and endwall surfaces and passes orange light scattered from the seed particles.

\section{DATA ACQUISITION}

The data acquisition technique is efficient in that It allows free-running of the $\mathrm{LA}$ system. Unlike several other $\mathcal{L}$ systems used in turbomachinery research $[1,3,4]$, the opt1cal system is not gated by a once-per-rev or once-per-blade signal, but 18 free to make velocity masurement whenever a seed particle crosses the probe volume. The technique is implemented by using a dedicated ninfcomputer to control date acquisition. The seed particle fringe croseing frequency (which is proportional to the particle velocity) 18 measured by a commerclal counter-type processor. The rotor shaft position 18 generated by an elestronic ohaft angle encoder which provides a continuous measure of the rotor shaft position relative to ace-per-rev algnal obtalned from the rotor disk. When a velocity measurement occure the min1 computer records the frequency and shaft position ag a date pair. At each axial and radial position surveyed, date are recorded at 1000 different shaft positlons. These posittons are typlcally distributed as 50 positions per blade passage ecross 20 consecutive blade passages.

It is olgnificant that the velocity measurements do not really occur at discrete shaft position, but rather are made anywhere 1 thin an Interval between adjacent rotor ahaft positions maiked by the shaft angle encoder. With 50 intervals per blade passage, the Interval length varies between $0.43 \mathrm{~mm}$ at the hub and $0.61 \mathrm{mon}$ at the tip of the blade. In th1s paper the term 'shaft position' is used with the underatandIng that mesaurenente attributed to ahaft position actually occur in an interval about that position.

A typical run coneiste of collecting 30,000 measurements yielding an average of 30 measurewents at each shaft posttion. Run times typicelly vary between 15 and 45 seconds. During data acquisition graphics terminal 1s used to generate a grephic diaplay which 18 typlcally updated every 15 seconde based or the date accumulated to that point in the run. The diaplay con-1sta of a h1stogras of the number of measurements at each haft position and a blade-to-blade velocity distribution averaged across the 20 measured blade passages along the circumferential measurement peth. This real-tiwe display adds to the effictency of the system ance it enables the operator to monitor the dula acquisiton process and terminate a run if necessary. At the conclusion of each run, a data table of $H_{f}$, $\sum_{i=1}^{N_{1}} f_{i}, \sum_{1=1}^{N_{j}} f_{i}^{2} 18$ stored on disk. Subscript $j$ is the shaft position number whlch runs from 1 to $1000, N$ Is the total number of measurements at position 1 , and $f_{1} 18$ the LA signal frequency of the 1 th measurement at position $f$. Further detalls of the data acquisition system can be found in reference [5].

\section{DATA REDUCTION}

The measured particle fringe crossing frequency is converted to velocity by multiplying by the fringe spacing. The velocity is corrected to standard day conditions using the relation

$$
v_{c}=v \sqrt{T_{s} / T_{p}}
$$

where $V$ is the corrected velocity, $I_{p}$ is the tetrperature measured in a plenum chamber upstream of the compressor inlet, and $T$ is the standard-day temerature. For each measured component of velocity the mean and standard deviation at each shaft position are then calculated from

$$
\begin{aligned}
& \bar{v}=\sum_{1=1}^{N} v_{1} / N \\
& v^{\prime}=\left[\left(\sum_{1=1}^{N}\left(v_{1}-\bar{v}\right)^{2}\right) /(N-1)\right]^{1 / 2} \\
&=\left[\left(\sum_{1=1}^{N} v_{1}^{2}-\frac{\left.N v^{2}\right) /(N-1)}{(N-1 / 2}\right]^{1 / 2}\right.
\end{aligned}
$$

The velocity magnttude and flow angle are calculated at each position using data from rums made at different beam orfentations. The geometry of the beam ortentation 18 shown in $\mathrm{F} 1 \mathrm{~g}$. 5. The measured velocity component $v_{\mathrm{m}}$ lies along ine AA which is in the plane of the beams and perpendicular to the blsector of the croasing beams. The beam bisector can be deflected in an off-radial direction by the beam director mirror. The beam bisector is restricted to the $(R, \theta)$ plane and the deflection angle 18 denoted by $\phi_{r}{ }^{\circ}$ The rotatable beam splitter is used to rotate the direction of the fringe normals about the $R^{\prime}$-axts (which is alined with the beam bisector). The angle between the fringe norma1s and the z-axis is denoted by $\phi_{2}$ and 18 measured in the $\left(2, \theta^{\prime}\right)$ plane. The mean and standard deviation of the $z, \theta, r$ velocity components are calculated from the three equations 


$$
v_{2} \cos a_{1}+v_{0} \cos \beta_{1}+v_{r} \cos \gamma_{1}=v_{m_{1}} \quad 1-1,2,3
$$

where subscript 1 denotes each different beaw ortencation and

$$
\begin{gathered}
\cos \alpha=\cos \phi_{2} \\
\cos \beta=\cos \phi_{Y} \sin \phi_{Z} \\
\cos \gamma=\sin \phi_{T} \sin \phi_{Z}
\end{gathered}
$$

The two equations

$$
v_{2} \cos \alpha_{1}+v_{\theta} \cos \beta_{1}=v_{w_{1}} \quad 1=1,2
$$

can be used to calculate $v_{z}$ and $v_{\theta}$ using data obtalned during two runs made at different $\phi_{z}$ angles with $\phi_{r}=0$. In practice the $\phi_{r}$ angles for the two runs are equal but are set to some non-zero value in the range \pm 4 degrees to mintmize the blade shadow reglons. Thus the calculated $v_{\theta}$ component of velocity actually lies along the $\theta^{\prime}$ direction. However, the difference between the calculated velocity in the $\theta^{\prime}$ direction and the velocity in the $\theta$ direction is small compared to the measurement error since the cosine of four degrees is 0.9976 .

The velocity distribution across the 20 measured blade passages is considered to be 20 separate observatlons of the flow in an average blade passage. Velocities at corresponding points relative to the blade in each Individual blade passage are averaged together to yleld a spatially-ensemble averaged blade-to-blade veloctity distribution. The averaged velocity distribution may be compared to the velocity distribution in individual blade passages to assess passage-to-passage flow variations.

\section{MEASUREMENT ERRORS}

The error in axtal and radial probe volume positoning $18 \pm 0.05 \mathrm{~mm}$. The errors in setting the beam splitter and beam director angles are \pm 0.03 degree and \pm 0.01 degree, respectively. The exror in a single LA measurement is a function of flow turbulence intensity and random nolse in the photomultiplier tube signal. It is difficult to make an error estimate for an indi$v$ idual measurement since this nolse is generated by background radlation which varies with each measurement. However, the statistical confidence $i_{n} N$ individual measurements made at a given shaft position is

$$
k=c v^{\prime} /(\bar{v} \sqrt{\mathrm{N}}) \text {, }
$$

where $k$ is the length of the confidence interval and c Is the confidence level. $N$ is approximately 30 for each point in the velocity distribution across an individual blade passage. N 18 approximately 600 for each point in the ensewble-averaged velocity distribution, since the averaged distribution is calculated from the 20 Individual blade-to-blade velocity distrfbutions. A1l error bars which appear in this paper are for $\theta$ $95 \%$ confidence level $(c-2)$. It should be noted that $V^{\prime}$ results from the sum of the flow fluctuation effects such as those caused by turbulence, velocity varlations due to rotor speed drift, and velocity gradients in the tangential direction across the geasurement shaft position interval. plus the previously mentioned random noise in the photomultiplier tube sigral. The maximum velocity gradient in the tangential direction occurs across the passage shock during transonic operating conditions and 18 on the order of $1 \%$ per shaft posttion interval. Observations indicate that the rotor speed drift during a run 18 on the order of $0.3 \%$.

Least squares polynomial curves are fit to the data prior to comparing veloctty distributions. One advantage to this approach is that the fitted curve contains information from all 1500 measurements made in a blade fassage ( 30 measurements at each of 50 points), whlle the data at a single shaft position are based un only about 30 measurements. Typlcally the difference between lise data and the fitted curve is 17 to $2 \pi$.

Two additional sources of measurement error are statistical and angle blasing. Statistical blasing arises because of the following. First, the velocity magnitude vartes with time. Second, for a uniformly seeded flow more particles cross the probe volume per unit time when the velocity is higher than the mean than when the velocity 18 lower than the mean. An arithmet $1 c$ average of measurements made over a given period of time therefore ylelds a calculated mean veloc1ty which is higher than the true mean. Statiotical blas can be removed using the relation [8]

$$
\vec{v}=\bar{v}_{b} /\left[1+\left(v^{\prime} / \bar{v}\right)_{b}^{2}\right]
$$

where subscript $b$ denotes biased measurements. Typ1cal values for $\left(V^{\prime} / \bar{V}\right)_{b}$ outside of blade wake and shock regions are $3 \%$ to $6 \%$, which result in a $0.4 \%$ correc-

tion. Because this correction is sma11, the data have not been corrected for statistical bias.

Angle biasing [9] occurs because the flow direction fluctuates with time. More measurements per unit occur when the flow direction is parallel to the fringe normal direction than when the flow direction fluctuates away from the fringe normal direction. The error In an arithmetic average of the velocity measurements made over a given time period is proportional to the angle between the fringe normals and the mean flow direction. Th1s error is $1 \%$ or less when the angle between the fringe normals and the mean flow direction 18 less than 20 degrees. In the presient work the fringe orientation angle is set at \pm 15 degrees from the average flow angle to minimize angle blasing error. However, the flow angle changes by 30 degrees across wakes and passage shocks. Therefore there are regions in which the angle between the fringe normals and the velocity vector 18 on the order of 45 degrees which could result in a $4 \%$ error in the measured velocity.

\section{SEED PARTICLE DYNAMICS}

The rotor passage shock can be used to determine particle lag and seed particle size using the method described in [3]. A Stokes drag model is used to predict the velocity response downstream of the shock for a particle of diameter $D_{p}$. The resulting equation is

$$
\begin{aligned}
18 v_{\mathrm{g}} \times_{\mathrm{n}} / \mathrm{D}_{\mathrm{p}}\left(\rho_{\mathrm{p}} / \rho_{\mathrm{g}}\right) & =\left(\mathrm{c}_{1}-\mathrm{c}_{2}\right) \\
& -\mathrm{c}_{2} \ln \left[\left(v_{\mathrm{u}}-\mathrm{c}_{2}\right) /\left(\mathrm{c}_{1}-\mathrm{c}_{2}\right)\right]-\left(v_{\mathrm{n}}-\mathrm{c}_{2}\right)
\end{aligned}
$$

where

$C_{1}$ - pre-shock gas velocity normal to the shock in the $(2, \theta)$ plane

$c_{2}=$ post-shock gas velocity normal to the shcck in the

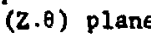

$V_{n}$ - particle velocity component normal to the shock in the $(2, \theta)$ plane 


$$
\begin{aligned}
& \text { - } v_{\mathrm{det}} \operatorname{in}\left(\beta_{\mathrm{Rn}}+a\right) \\
& x_{\mathrm{n}} \text { - perticle dietence normal to the ahock } \\
& \text { - - ccs a }
\end{aligned}
$$

The relative flow angle $\beta_{\mathrm{gm}}$ and the hock fnclination angle a are defined in P18. 6. The mensure, velocity component $\nabla_{\text {a }}$ a a function of $x_{\text {f }}$ 1e determined from the enomblengeraged blade-to-blade distribution of relative velocity $v_{\text {RER }}$ uning the geometry shown in 71g. 6, where to the distance downatraam of the -hock along the clrcumforential measurement path. Th1s procedure aesumes that the distribution of $v_{n}$ 1s uniform alons the face of the whock over the distance - aln a. Typical valued of and a uned in the above calculatione are $14 \mathrm{~mm}$ and 10 degrees, respectively, which y1eld 10 o $\alpha=2.4 \mathrm{~mm}$.

The particle diameter $D_{p}$ 1s determined in the following manner: For vartout vajues of $D_{p}, v_{p}$ is calculated at given values of $x_{n}$ uaing the known valwes of $P_{p}, P_{g}, v_{g}, C_{1}$, and $C_{2}$. The particle diameter 18 then taken as the value of $D_{p}$ which yielde the best agree snt between the calculated and measured diatribution of $v_{n}$ al a function of $x_{n}$. The results of two particle size determinations are shown in F1g. 7. Each data point in the figure 1s based on approximately 600 measurements. The dats were obtained under Identical flow and signal processor conditions at two different axial stations. The only change made in the LA syotem between the two runs was the removal of the orange filter uned in the fluorescent dye technique. The agreewent between the date obtalned at axial station $z-10.2 \mathrm{~mm}$ and $z=12.7 \mathrm{~mm}$ Indicates that $v_{\mathrm{a}}$ 1s uniform alons the face of the shock over dietances of 2 to $3 \mathrm{~mm}$. With the orange filter in place, the minimum dimeter of the particles detacted by the optice is bout $1.4 \mathrm{\mu m}$, while the diameter of particles detected without the filter in place $181.2 \mu \mathrm{m}$. Th1s difference in diaseter reflects the loss in o1gnal atrength in passing through the orange f1lter. With the $L A$ counter-processor threshold level held constant, a larger particle diameter 1s necessary to trigger the counter circultry when the filter is in place.

The resulte shown In Fig. 7 indicate that the distance required for the particle velocity to decay to within $5 \%$ of the post-shock gas velocity $1 \mathrm{~s}$ about $12 \mathrm{~mm}$ normel to the shock. Th1s 18 about 13 mor or $13 \%$ of the blade chord in the relative flow direction. Note that the flow angle as well as the velocity magnitude is in error in the lag region. Additional particle size determinations performed with the orange filter in place yield particle olzes ranging from 1.2 to $1.5 \mu \mathrm{m}$. A1though the minizum particle size detected by the optics increases with the orange filter in place, couparisong of blade-to-blade velocity distribution mensured under 1denticel flow conditions with and wh thout the filter in place ladicate no differences greater than the experimental error in the velocity distribution results due to the we of the filter.

The passage ahock 10 not the only region in the blade pasese where particle tracking may be a problem. Maxwell [10] analyzed seed particle flow in an axialflow compressor rotor olutlar to the teat rotor used in the prusent study. He obtalned a numerical colution for the gat flowtield and then integrated the particle equat 1on of motion to determine the particle path and velocity. The results Indicate that for $1.5 \mathrm{~km}$ d1esw acer particles the particle-to-gas volocity ratton are $0.90<v_{p} / v_{8}<0.96$ in the leading edge rogion and $0.98<v_{p} / v<1.02$ through the remalnder of the bledo peesage. ${ }^{P}$ plrticle engular deviation was tound to be a meximum of 6 degrees along the suction ourface and acrose the blade pasenge at the tralling edge.

\section{DESULTS AND DIBCUSSION}

Plow phenemene atudied during the Inlt1el application of the $L$ ayeti $a$ include variatione in flow from paesege-to-pasuse, shock surface location, veloc1ty changes across shock waves, three-dimannional flowd in the blade wake, and the development of the endrall boundery layer. In addition, LA menuturemente vere compered to nuwerical results within the blade row and to conventional probe mesaurements at atatiuns outalde of the blade row. The reoults obtained will be brintly diecuaced.

\section{Pessage-to-Passage Flow Variation}

One advantage of the current data acquialtion scheme is the ability to record velocity maesuraments across consecutive individual blade pasanges. Pasangto-passege veriations in flow conditions can be observed and anelyzed by using date from the individual blade pasases. As on axample, the diatribution of abBolute velocity ecross five consecutive blade pesugen 1s shown in F18. 8 at four axisl atatione (given in percent axial chord) along otreameurface 1 (bant the t1p). The operatiog point 1s neer otell at 75\% of de81gn speed. At $-25 x$ and $2 x$ chord the flow in payeage 9 18 clearly different from that in paseagen 8 and 10 . The variation in flow between pasageb at $2 x$ chord may be caused by small variation in leading adge geometry and axial location. Least squeres curve fite of the velocity distribution 1n paneses 8 and 9 are comparad to curve f1ts of the avaraged velucity distribution in 718. 9 where the blade locatione are denotad by the cross-hatched areas. The orror bars in $F_{18}$. 9 repregent twice the standard devlation between the fitted curve and the data and therefore encompane $95 \%$ of the date points. Uaing the everaged curve $11 t$ of a raference, we see that the flow variation between panages 8 and 9 1s a maximum of $20 \%$ near the leading adge. The data shown here rapresent the greateat passage-topassage velocity variation observed in the present work. At operating points near maximum afficlency the 1nc1dence angles are amall and there 1o lens turning around the blade leading adge relative to that for the near stall case. Passage-to-paseage flow variatione at these operating points are on the order of $5 x$ or 1ens.

\section{Blade-to-Blade Velocity Distributions}

It Is generally desirable to use the enombleaveraged velocity distributions when performing date anolyses because the ensemble-averaged date out, which contalne 50 pointe in the everaged valocity diutribution, 10 much omaller than the uneveraged date aat whych contalns 1000 pointe in the velocity diutributlons acrose 20 blede paseages. A posestble eource of error in uelng the averaged data 10 the tandeacy to omenr out detalle of the velocity dietribution by evazag1ng across the 20 blade pasange. However, comparison of the averaged and unavaraged diotributione in F1g. 9, a worat-case exampla, indicates that velocity dietribution detalla are not eIgnificantly modified by averaging.

Ensemble-avoraged blade-to-blade diatributione of velocity and flow angle mensurec on stranmeurface 1 (near the tip) at $23 \%$ chord under traneonic operating condition are shown 1a F1s. 10. The operating point 10 at deafon opeed near etall mese flow. The paseage chock location is Indicated oy the rapid change in velocity and flow ansie at mid-panace. Mote that the 
absolute flow rometns axial until it encountere the chock even though the masurewent atation 1s located vell behind the leading edge. The hock turn the absolute flow by more than 30 degrees which repreaents 757 of the tuming measured at the blede tralling edge.

\section{Rotor Shock Surface Mapping}

The three-dimensionality of the rotor shock aysten 10 ohom graphically in $F 1 \mathrm{~g}$. II where the shock location on streamourfaces $1,2,3$ (near-t1p, mid-span, and near-hub, respectively) is plotted for the maxtmin mass flow condition at $100 \mathrm{x}$ design speed. The inlet relat1ve Mach number varies from 1.16 on the nest-hub strensurface to 1.39 on the near-tip atreamsurface. The blade sectlone and shocke are radially projected to eliminate the spanwise vaciation of blade spacing. The shock location is determined from velocity distributlons of the type shown in $\mathrm{Fig}_{\mathrm{g}}$. 10. The flow behind the passage shock 18 supersonic on all three streamsurfaces. At mid-span and near the hub (otreamsurfaces 2 and 3 , respectively) the flow then diffuses to absonic velocities within the blade pasaage without passing through another shock. However on streamsurface 1 (near the t1p) the flow passes through a noras shock near the blade trasling edge.

The owept back blade leading edge creates a shock aurface which leans back in the flow direction from hub to tip. Flow turning across the lnclined shock in the meridional plane generates an Increase in the radial velocity component toward the tip downstrean of the shock. As noted in $[2,4]$, the values of relative velocity and flow angle measured wcross the shock do not satisfy the 1sentropic normal shock relations even after correction for particle lag effects. It 18 found that an outward radial velocity component upatream of the shock must be assumed in order to satisfy the shock relations. The corresponding calculated streamline lope fust upstream of the ohock in the meridional plane 18 on the order of 40 degrees. The calculations are sensitive to velocity magntude and flow angle and to shock Inclination angle in the meridional plane. A 27 to 37 deviation in velocity reaults in a $15 \pi$ deviation in the calculated streamine slope. Although attempts to measure the radial velocity component near the passage shock were not successful, atrong deposition of seed particles was observed on the window in the outer casing around the passage shock region. Th1s way indicate that a redial outward flow is present in the vicinity of the shock.

\section{Rotor Wake Measurements}

Averaged velocity distributions measured downstream of the rotor at $70 x$ design speed and at both maximum efficiency and near-stall conditions are shown In F18. 12. The masurements were made on streamsurface 1 (near the tip), at station 2. The averaged velocity distribution is repeated so that the wake appears In the center of each plot. The radial velocity $v_{r}$ and streamline slope in the meridional plane $a_{\text {are }}$ defined as positive outward toward the tip. The streamilne slope outelde of the wake agrees with the design streamline slope of -12 degrees. Outward radial velocities in the blade wake are to be expected due to the radial pressure Imbelance on the wake fluid. The radial outward flow, lelative velocity defect, and wake width are all larger the near-stall point than at the maximum efficlency operating point.

\section{Endwal1 Boundary Layer Development}

The development of the outer endwall boundary layer at design speed and maximum mass flow is shown in
P18. 13. The effective probe volume length of $2 \mathrm{~mm} 18$ Indicated in the figure. The velocity at efch data point 18 obtained by arithnetically averaging all 30,000 measurements obtained along the circumferential measurement path. The suanwise location of each polnt is the location of the probe volume center. Averaging across the flatte probe volume length results in measured velocities which are higher than the true velocity, partlcularly near the vall. The boundary layer downstream of the blade is thinner than that upscream of the blade. Th1s thinning of the boundary layer reflects the energy addition which occurs in passing through the rotor.

Comparison of LA Measurements and Numerical Results

The resuts of a finite difference solution [11] of the streamfunction equation on etreamsurface 2 are compared tc $L A$ measurements in $F 1_{B} .14$. The measure ments were performed at $70 \%$ design speed near the maximum efflclency operating point. The cross-hatched areas vear the blade surface denote regions in which no measurements were obtalned. The numerical and experimental results dinplay reasonable agreement in the expansion region arourd the blade leading edge, but the LA weasurements Indicate less diffusion than predicted by the numerical solution near the pressure side of the blade passage in the rear portion of the passage. This behavior may be due to the fact that the numertcal model is inviscid and therefore cannot account for the displacement thickness effect of the blade wakes.

Comparison of LA and Conventional Probe Measurements

IA measurements are compareu to conventional pressure survey measurements at stations 1 and 2 (see F1g. 1). The conventional instrumentation measures velocity and flow angie averaged along the entire circumference at a given axial and radial positon. All 30,000 LA measurements obtained along a circumferential measurement path are therefore arithmetically averaged for comparison with the conventional survey measurements. The $L A$ and conventional measurements are not made simultaneously ince different compressor casings are used for the LA and survey runs, and measur ment repeatability is therefore a factor to be considered in comparing results. The measurement repeatability of eact: instrumention system when the compressor $\mathrm{Fig}$ conditions are not changed is $1 \%$. The repeatability in resetting the compressor rig conditions 1827 . Two additional factors which affect the comparison of results are the piesence of a seed infection probe wake during $L A$ measurements and probe blockage effects during pressure survey measurements. Although the seed Infection probe 18 located 72 probe diameters upst:eam of station 1, a limited number of IA surveys wade at station 1 in the $\theta$-direction indicate that a 27 to $4 x$ velocfty defect from the seed infestion probe 18 present at station 1. During pressure survey measurements there are four probes each at stations $I$ and $?$ and elght additional probes downstrean of station 2 . When the probes are fully extended for measurements near the hub, the total frontal area for the four probes at each otation $182 \%$ of the annulus ares at the rotor face. An observed decrease in wall static pressures during probe injection indicates that throughflow velocity varlations due to probe injection do exist.

The LA measurements of absolute velocity and flow angle at otation 1 agree with the pressure nurvey measurements to within $4 \%$. This is considered reasonable In view of the factors discussed above. The absolute velocities wessured at station 2 by the $L A$ and survey probe agree within $7 \%$, but the flow angles measured by the two syotems disegree by as much as $14 \%$. The disagreement between the measured flow angles 10 due to 
differences in the enasured $V_{\theta}$ velocity component

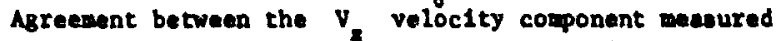
by the $L A$ and the survey probe is comparable to the agreement at etation 2 , but the $v_{\theta}$ cooponent mesured by the IA $1810 \%$ to $15 \%$ lower then that aneured by the survey probe. The reasone for this difference require further study.

\section{SURY RY AND CONCLUDING REMRKS}

The application of a laser anemometer aysten to the measurement of flow in a transonic axial flow compressor rotor is described. Use of a dedicated minicomputer to control date acquiaition allow rapid accunulation of data wth high spatial resolution in the bladeto-blade direction and the recording of data across 20 Individual blade passages. A fluorescent dye techntque reduces problems due to incident 11 ght reflection from metal blade pasage surfaces and allows masurements to be made in the endwall boundary layere. The ab1lity to direct the laput laser beans away from the radial direction allows minimization of blade blockage effects and eanbles the measurement of radial veloctty como nents.

Future research plans include holographic interferometric studies of the rotor shock system. Shock patterns measured by the holographic technique will be cospared to those measured by the LA. Future LA research will involve measurements in compressor stages with stator blades present so that both rotor and stator flowflelds and the extent of the circumferential variation in the rotor flowfleld induced by the stator may be Investigated. Survey probe and LA measuremente w111 be made simultaneously to further investigate differences between the veloctities measured by the two systems and to Investigate the signiflcance of survey probe blockage effects.

\section{ACONOWLEDGEYWTS}

The authors wish to acknowledge the contributions of Genevieve Bsgar for running the numerical streamfunc:ion solutions used in comparison with the LA date and of Mark Laessig for assioting in date reduction and analysis.

\section{NOMENCLATURE}

c confidence interval

$C_{1}$ pre-shock gas velocity normal to the passage shock in the $(z, \theta)$ plane

$C_{2}$ post-shock gas velocity normal to the passage shock in the $(2, \theta)$ plans

D sed particle diameter

$f$ seed particle fringe crosing frequency

in confldence interval length

N number of measurements

PR total pressure ratio across the rotor

PS blade pressure surface

r radial distance

s distance along circumferential measurement path

SS blade suction surface

$T_{p} \quad$ plenum temperature

T. atandard day temperature, 518.7 degrees Rankine

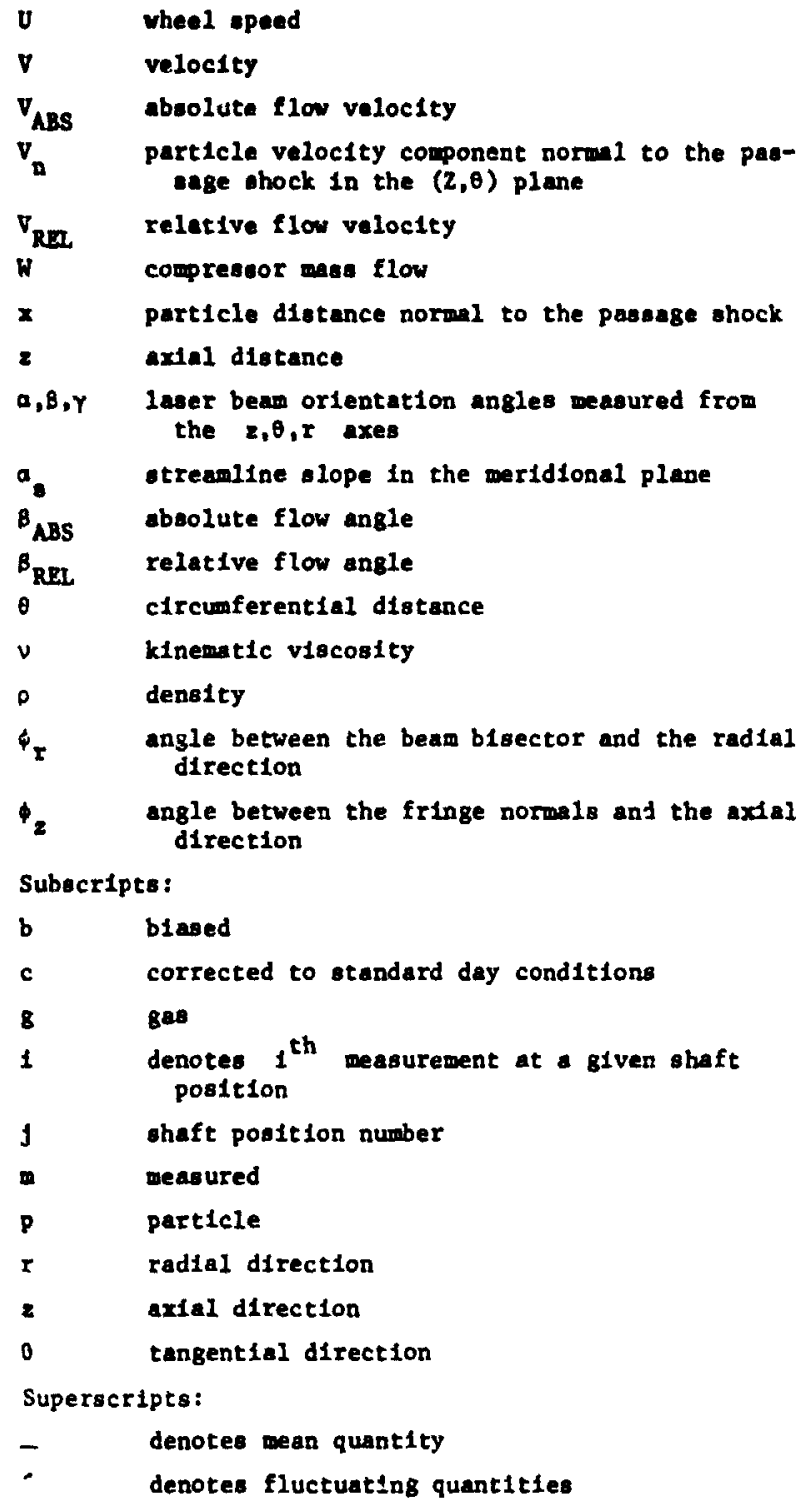

\section{REPERENCES}

1. Wisler, D.C. and Mossey, P.W., "Gas Veloclty Measurewent: Within a Compresser Rotor Passage Using the Laser Doppler Veloc1meter," Journal of Eng1neerlag for Power, Vol. 95, No. 2, Apr. 1973, pp. 91-96.

2. Wlsler, D.C., "Shock Wave and Flow Veloclty Measurements in a HIgh Speed Fan Rotor Uning the Laser Velocimeter," ASWE Paper No. 76-GT-49, Mar. 1976.

3. Walker, D.A., Hillim, M.C., and House, R.D., "Interblade Velocity Measurements in a Transonic Fan Ut1l1zing a Laser Doppler Velocimeter," M1nnmiota Sympos tum on Laser Anemomerry, E.R.G. Eckert, ed. University of Minnesota, Minneapolis, Minn., 1976, Pp. 124-145.

4. Dunker, R.J., Strinning, P.E., and Weyer, H.B., "Experimental study of the Flow Field Within a Transonic Axial Compreseor Rotor by Laser Veliciwetry and Comparison with Through-Flow Calculations," Journal of Englnering for Power, Vol. 100, No. 2 , Apr. 1978, PP. 279-286. 
5. Powe11, J.A., Strasian, A.J., and Sechbolte, R.G., "Efficient Leear Apemomerer for Iatra-Rotor Plow Mapplos in Turbonechioury." To be Prenented et

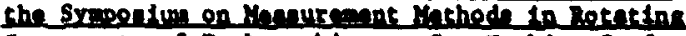
compenente of Turborachtneryi Gee Torblue confersnce end Producte Shoy, Americen Soclety of Hechen1cel Englneare, New Orleane, La., March 9-13, 1980.

6. Hoore, R.D., Lawle, G.W., Jr., and Oabora, W.H., "Performance of a Transonic Pen Staze Dealgne" for a Low Kerldfonal valocity Rat1o." MSA TP-1298, 1978.

7. Stevenwon, W.H., dos Santos, R., and Noteler, S.C., "Friage Mode Fluoresence Velocientry," Applicetions of Mon-Instruetve Inetrumantation in Fluid Flow Research, ACARD-CP-193, 1976, PP. 20-1-20-9.
8. Barnate, D.O. and Bant1oy, H.T., "Statiotical s1ae of Individuni Reallsetion Leaer Velocimeters," second Intersantional Workuhop on Leear veloctingEry, Vol. 1, H. D. Thoipeos and W. B. Stevemon, ads., Purdue Vatvere1ty, 1974, pp. 428-444.

9. Seaholtz, R.G., "Laser Doppler valocienter Byoten tor Turbine Stetor Caccade Studiee and Analyale of statiotical Blaniog errore." MSA TIS D-8297. 1977.

10. Mawre11, B. R., "Irecer Particle Nlow 1n e Compreeoor Dotor Presege with Applicution to LDV," Aper tcan Inatiture of Arronautice and Antronautice, Jourze1, Vo1. 13, No. 9, 8ept. 1975, Pp. 1141-1142.

11. Katean1e, T., "Mortruy Progres for Culculating Tran conle Velocitces on a Blede-to-Blade stream Surface of a Turbonech1nar," MSA TI D-5427, 1969. 


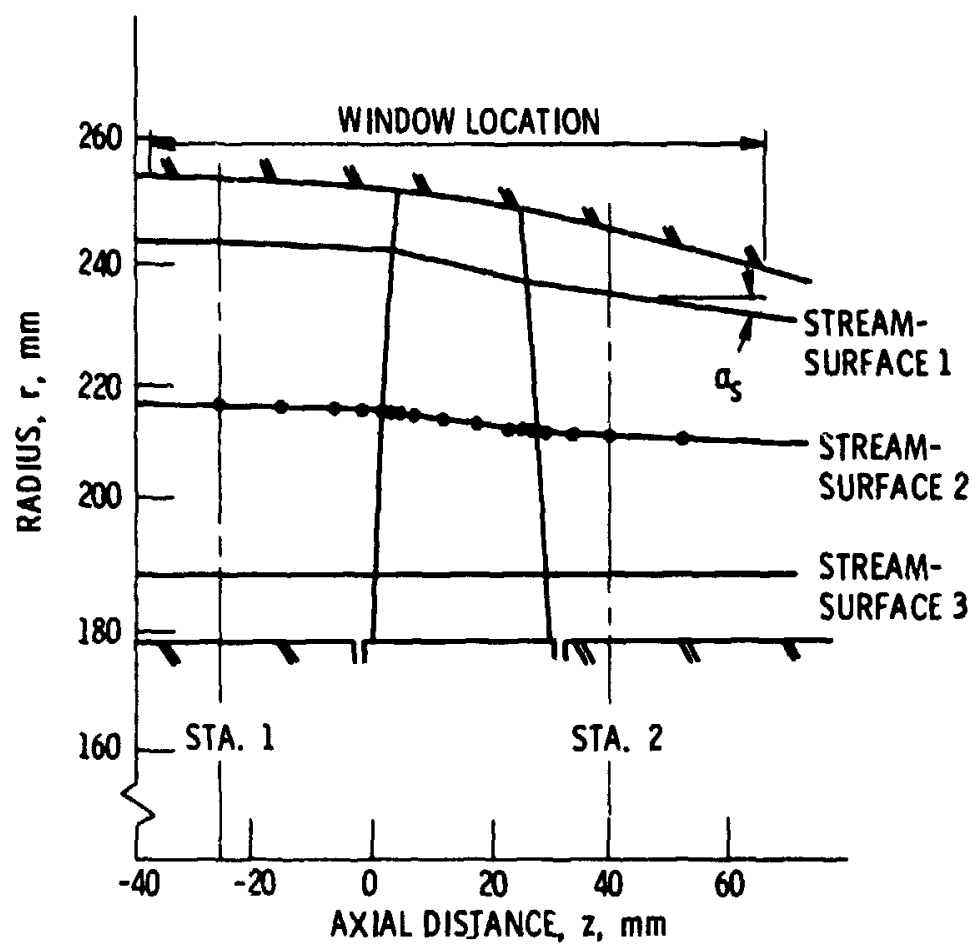

Figure 1. - Test compressor flowpath and streamsurface locations.

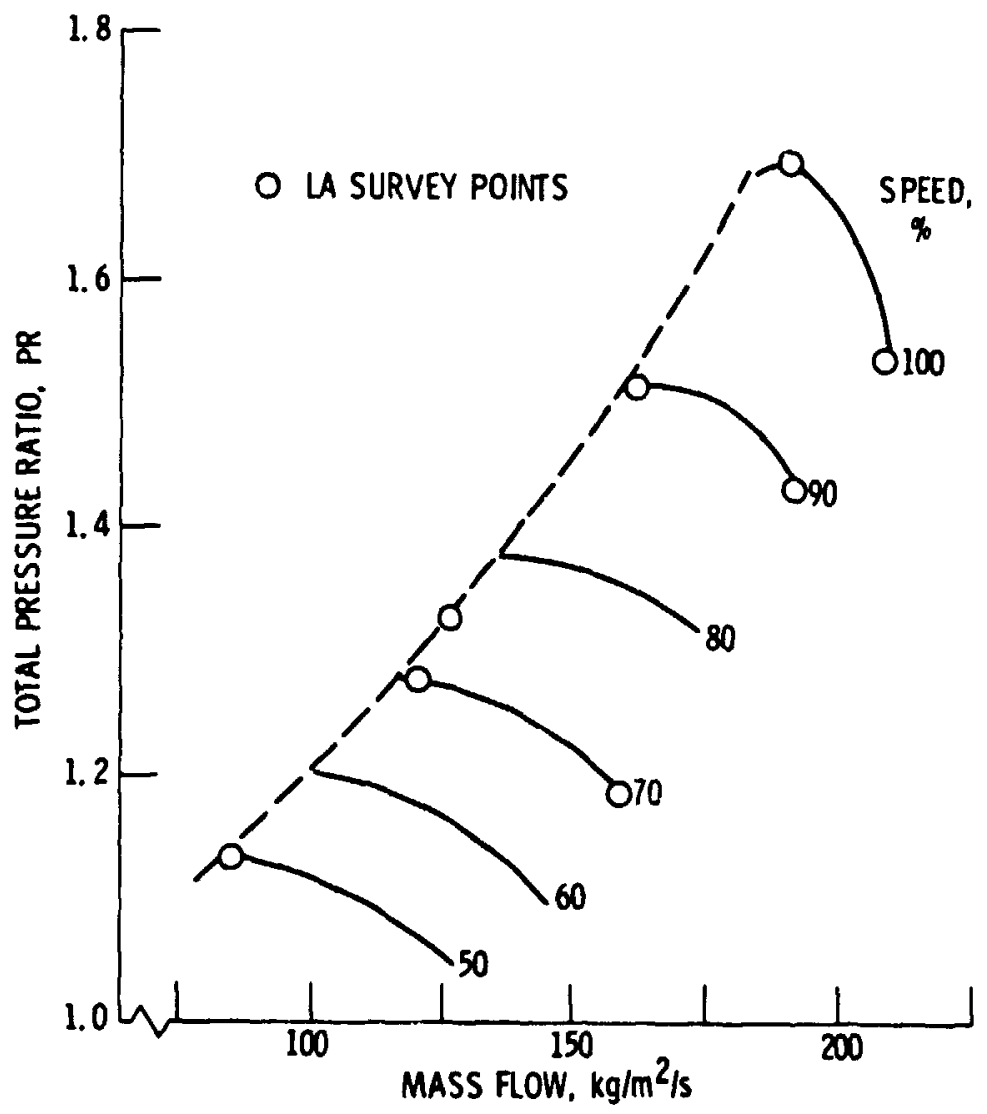

Figure 2. Test compressor performance map. 


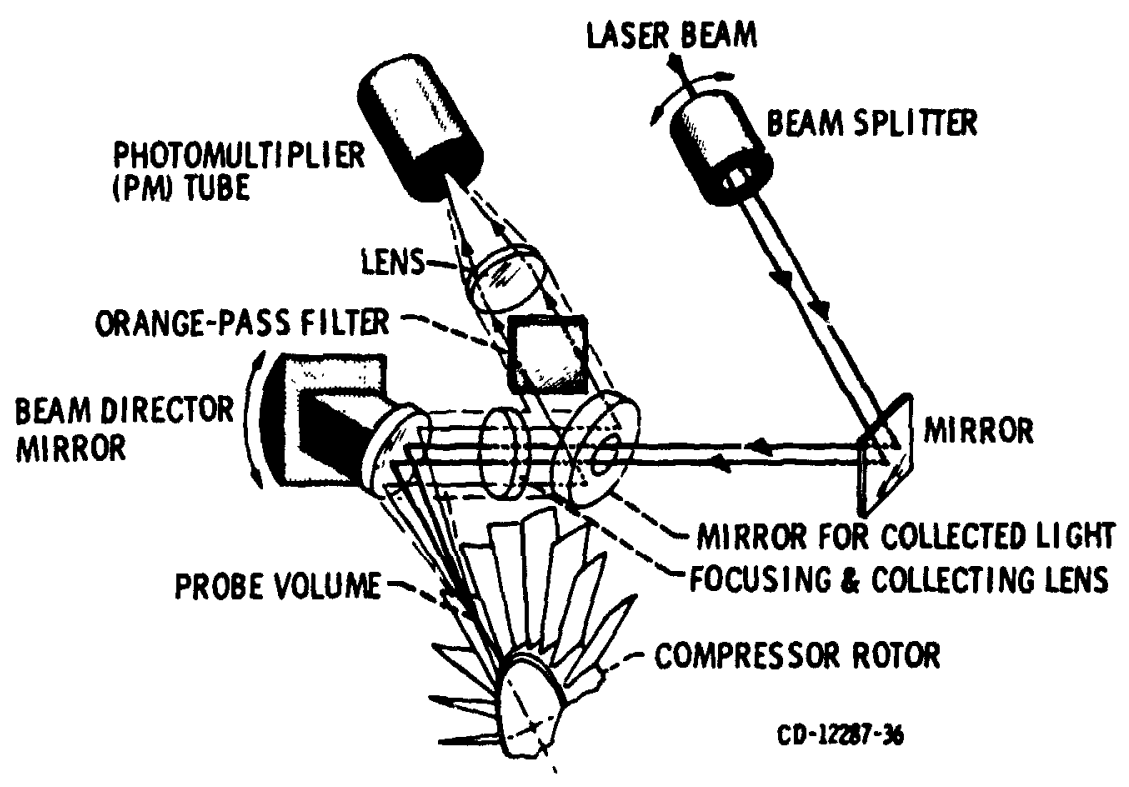

Figure 3. - Laser anemometer system optical layout.

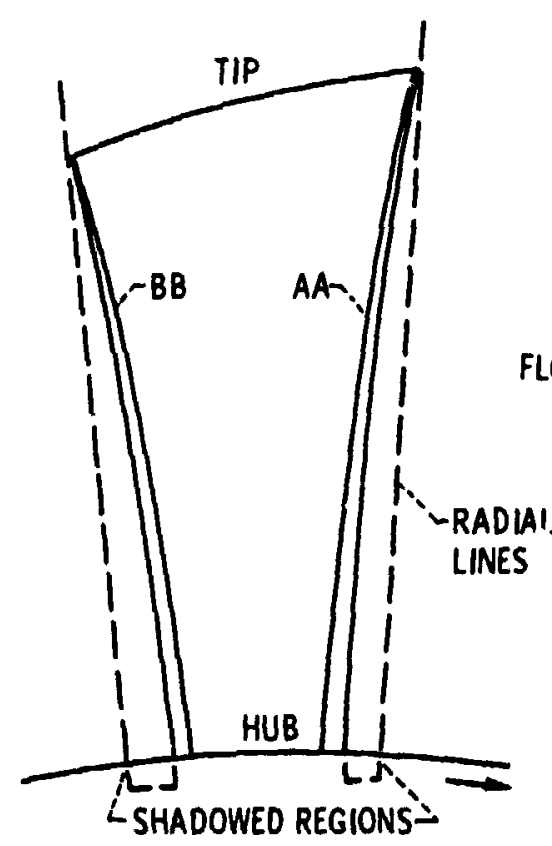

VIEW LOOKING DOWNSTREAM

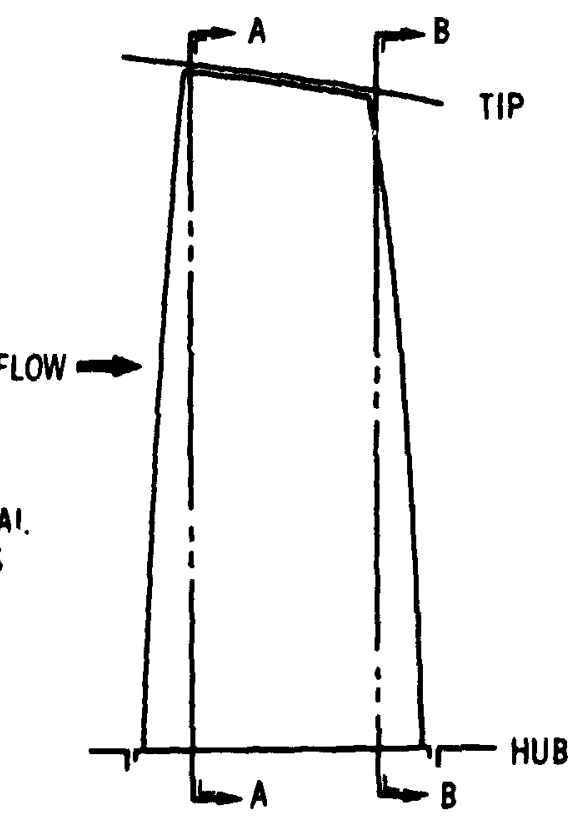

AXIAL VIEW

Figure 4. - Blade geometry showing shadowed regions due to blade twist. 

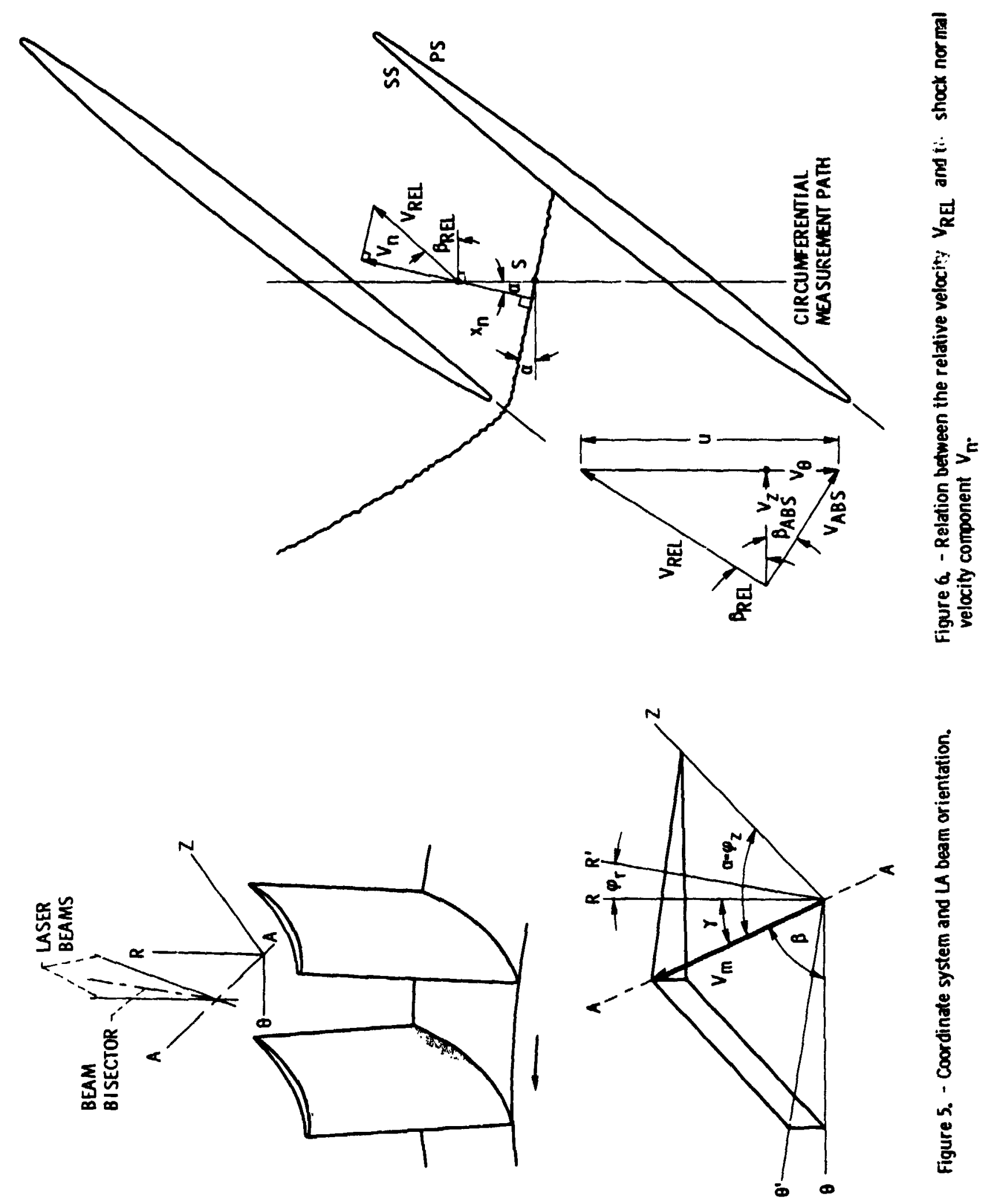

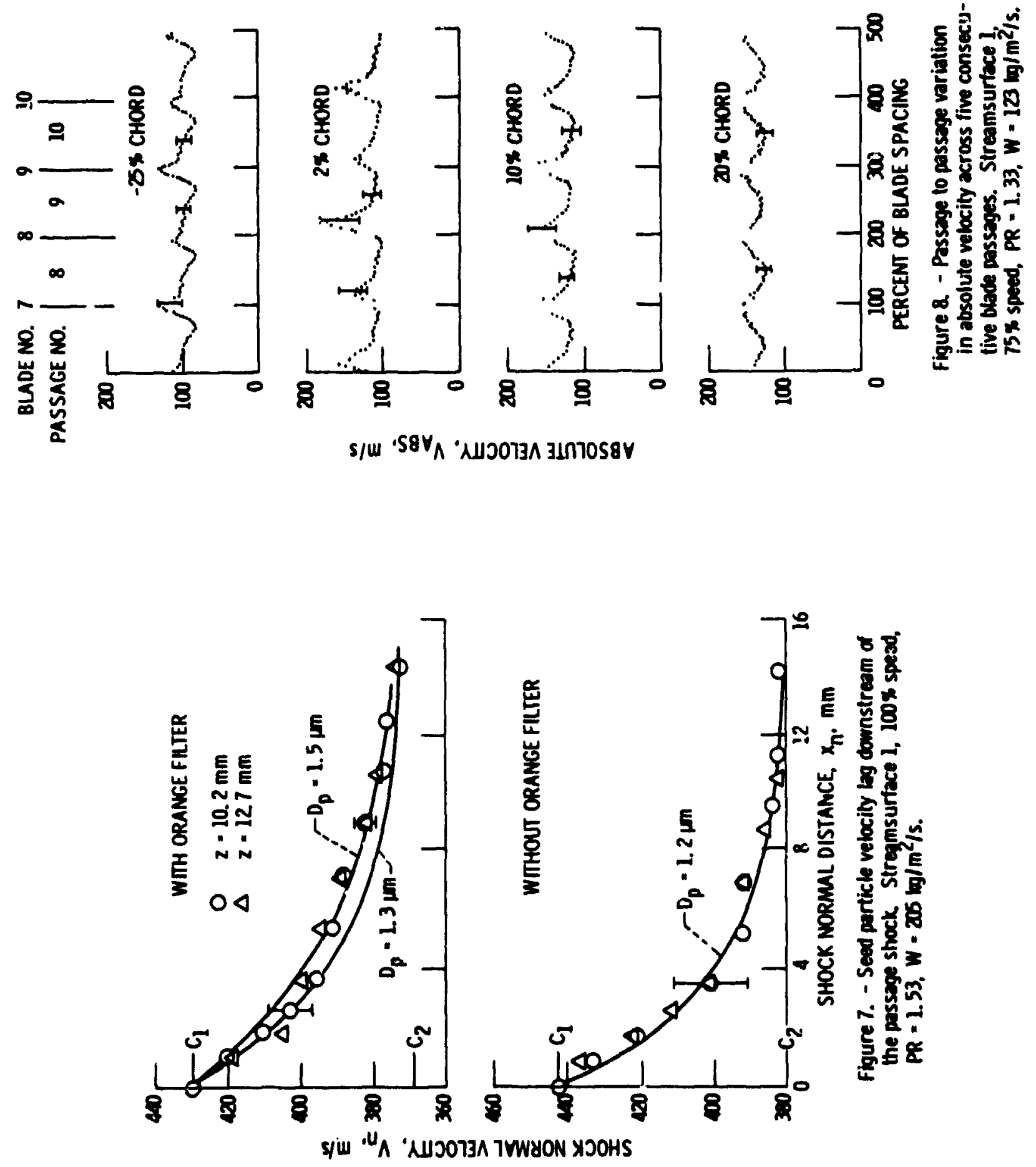

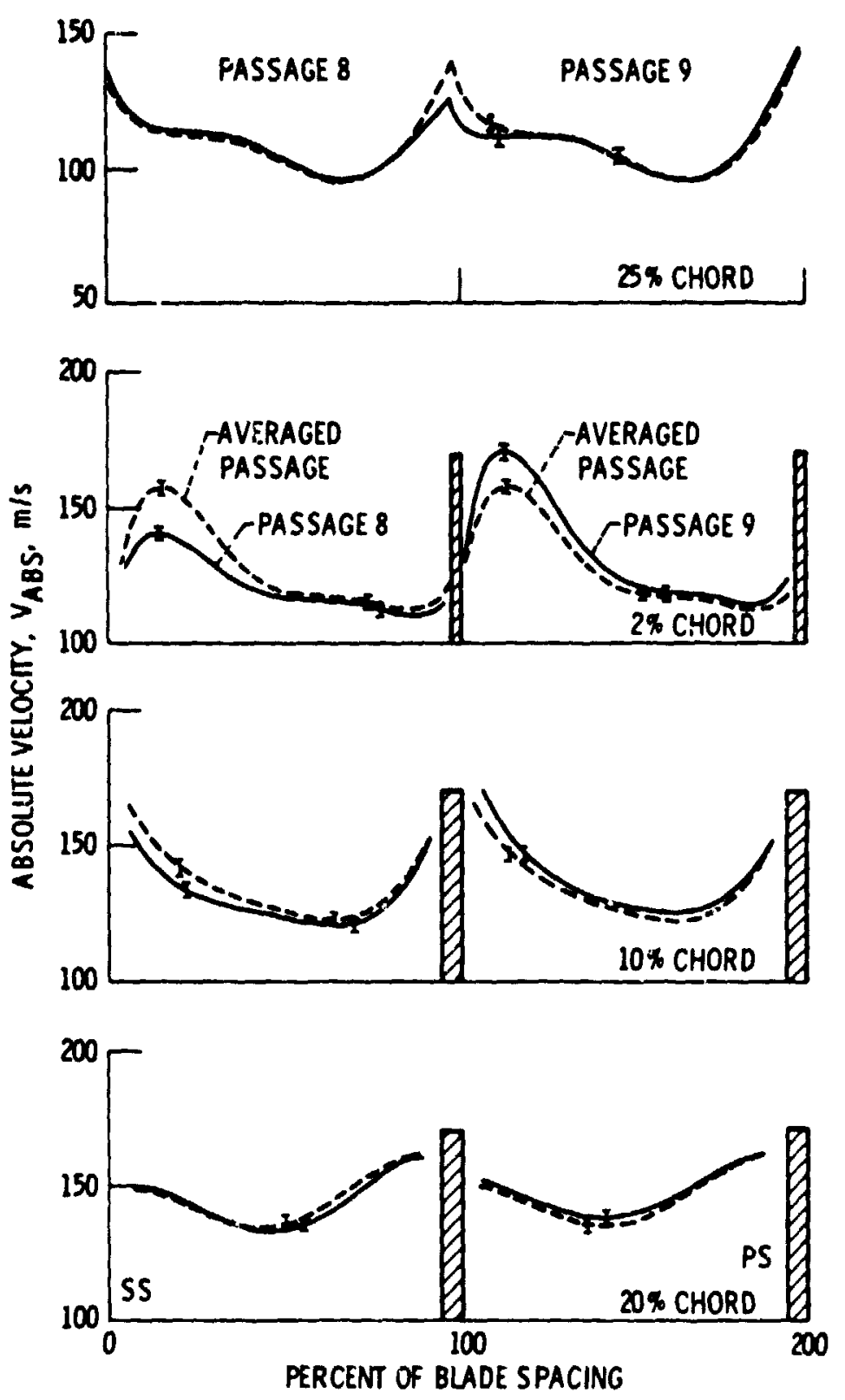

Figure 9. - Comparison between curve fits of the ensembleaveraged and individual blade passage distributions of absolute velocity. Streamsurface 1, 75\% speed, PR - 1.33, W = $123 \mathrm{~kg} / \mathrm{m}^{2} / \mathrm{s}$. 

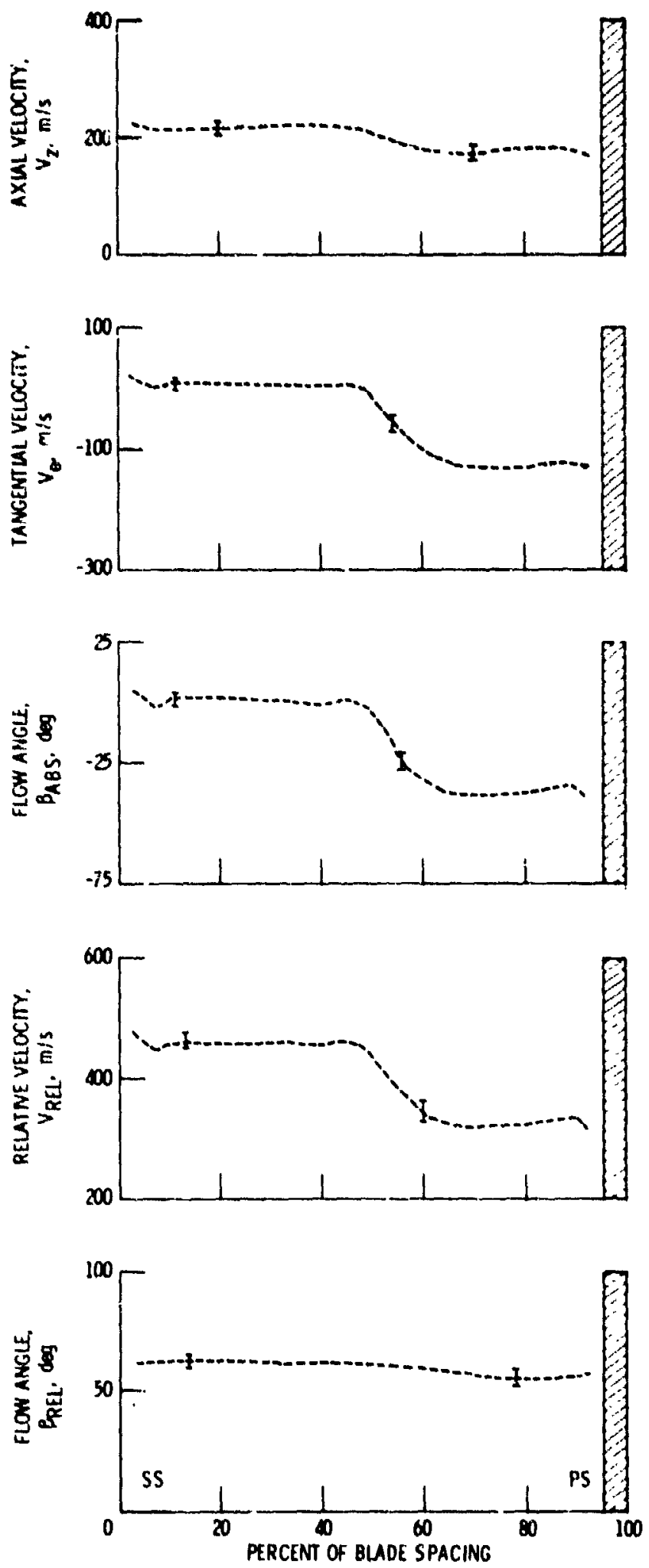

Flgure 10. - Ensemble-averaged blede-10-blade distributions of velocity and flow anglo across a passage shock. Streamsurface 1, 23\% chord, 100\% speed, PR - 1.06, W - 190 $\mathrm{kg} / \mathrm{m}^{2} / \mathrm{s}$. 

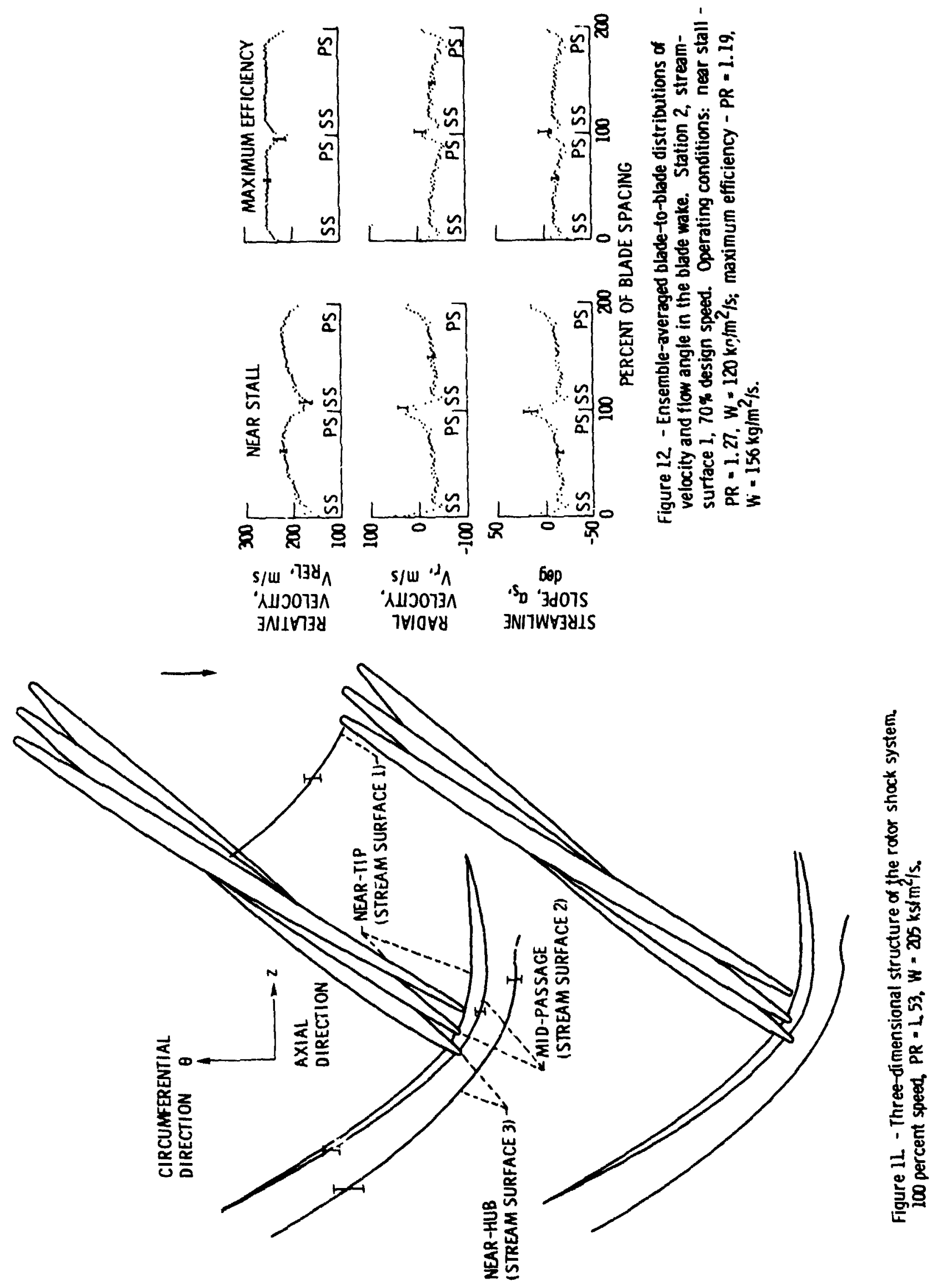


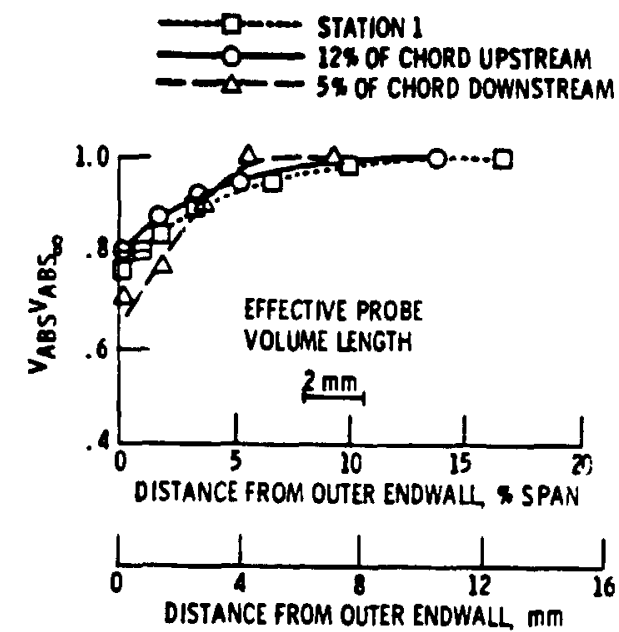

Figure 13. - Development of the outer endwall bundary, layer. 100\% speed, $P R-1.53 . W$. $205 \mathrm{~kg} / \mathrm{m}^{2} / \mathrm{s}$.
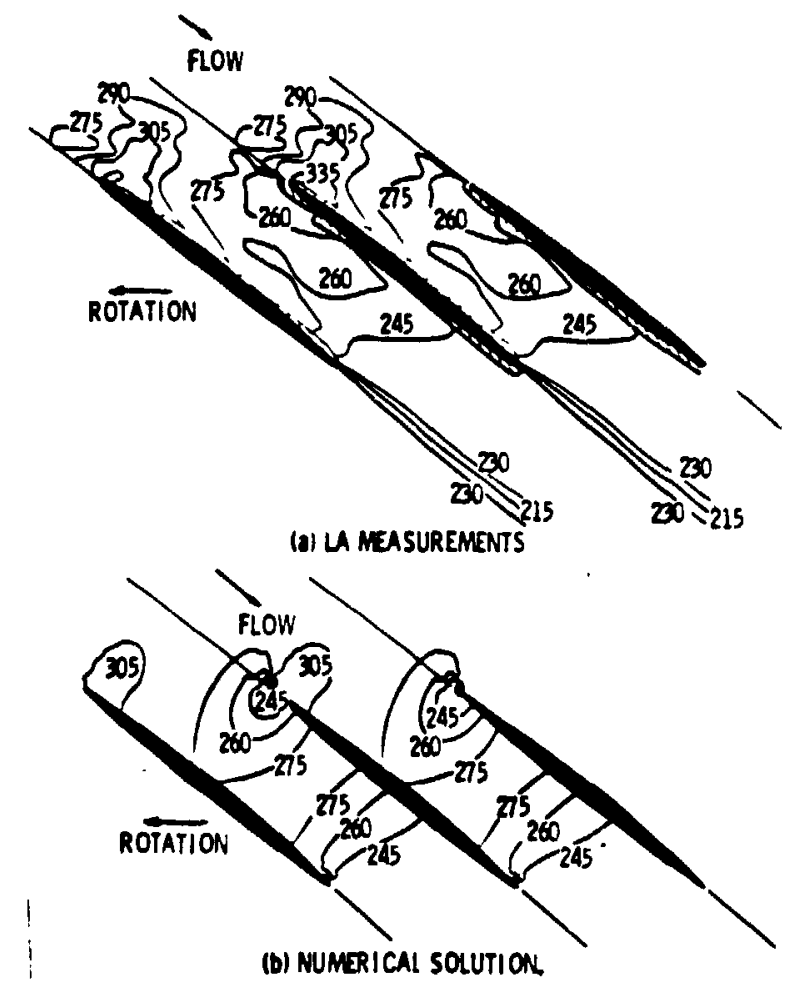

Figure 14 - Comparison of masured and calculated distribution of relative volocity. Stroum surface 2, 70 percent speed $P R-L 19, W-15 \mathrm{~kg} / \mathrm{m}^{2} / \mathrm{s}$. Contours in $\mathrm{m} / \mathrm{s}$. 